\title{
Song-Induced Phosphorylation of cAMP Response Element- Binding Protein in the Songbird Brain
}

\author{
Hironobu Sakaguchi, ${ }^{1,2}$ Kazuhiro Wada, ${ }^{3}$ Masao Maekawa,, ${ }^{1}$ Toshikazu Watsuji, ${ }^{3}$ and Masatoshi Hagiwara ${ }^{3}$ \\ ${ }^{1}$ Department of Physiology, Dokkyo University, School of Medicine, and 2Intelligence and Synthesis, Precursory Research \\ for Embryonic Science and Technology, Japan Science and Technology Corporation, Mibu, Tochigi 321-0293, Japan, \\ and ${ }^{3}$ Department of Functional Genomics, Medical Research Institute, Tokyo Medical and Dental University, Bunkyo-ku, \\ Tokyo 113-8519, Japan
}

\begin{abstract}
We have investigated the participation of CAMP response element-binding protein (CREB) in the response of the songbird brain to a natural auditory stimulus, a conspecific song. The cells in the two song control nuclei, the higher vocal center (HVC) and area X of zebra finches (Taeniopygia guttata), were intensely stained with an anti-CREB monoclonal antibody. Double-labeling studies showed that CREB immunoreactivity was detected only in area X-projecting neurons in the HVC. The cloned CREB cDNA from zebra finches (zCREB) is highly ho-
\end{abstract}

Memory is information about an animal's experiences that is stored in the nervous system. The avian song learning is an attractive model system for long-term memory formation (Konishi, 1965). However, little is known about the molecular mechanisms required for song learning. Chew et al. (1995) showed the dependence of this long-lasting neural change on protein and mRNA synthesis. Recent neurobiological studies suggest that activation of a transcription factor, cAMP response elementbinding protein (CREB), is necessary for the formation of longterm memory in a remarkable diversity of animals from invertebrates to mammals (Kaang et al., 1993; Bourtchuladze et al., 1994; Yin et al., 1994). In this paper, we have tried to throw some light on the roles of CREB in song learning by birds.

A young male zebra finch learns to sing only during a period that is sensitive to song learning (Immelmann, 1969). Strictly speaking, there are two overlapping phases in song learning: the sensory acquisition phase when a young bird hears and memorizes a song template, and the sensorimotor learning phase when the bird practices its own song and matches it to the memorized model (Konishi, 1965). The brain circuits known as the song system (Fig. 1) which is responsible for song acquisition and production, consists of two functionally distinct neural pathways. One is the primary motor control pathway that includes the higher vocal center (HVC), the robust nucleus of the archistria-

Received Sept. 23, 1998; revised Feb. 26, 1999; accepted March 2, 1999.

This work was supported in part by a grant from the Ministry of Education, Science and Culture in Japan. We thank Dr. M. Montminy (Harvard University, Cambridge, MA) for providing antiserum 5322; Dr. K. Dong (Kobe University, Japan) for providing the FRe; Dr. R. Li (Tokyo University, Japan) for her technical advice; R. Kawakubo for drawing figures; Dr. I. Taniguchi (Tokyo Medical and Dental University) for his encouragement during this work; and Dr. J. L. Maderdrut (Tulane University, New Orleans, LA) for improving this manuscript.

Correspondence should be addressed to Dr. Masatoshi Hagiwara, Department of Functional Genomics, Medical Research Institute, Tokyo Medical and Dental University, Bunkyo-ku, Tokyo 113-8519, Japan, or Dr. Hironobu Sakaguchi, Department of Physiology, Dokkyo University, School of Medicine, Mibu, Tochigi 3210293, Japan.

Copyright (C) 1999 Society for Neuroscience 0270-6474/99/193973-09\$05.00/0 mologous to mammalian $\delta$ CREB. Phosphorylation of $z$ CREB at Ser ${ }^{119}$ in area X-projecting HVC neurons was induced by hearing tape-recorded conspecific songs of zebra finches, but not by birdsongs of another species or white noise. These results raise the possibility that $z$ CREB plays a crucial role in the sensory process of song learning.

Key words: CREB; birdsong; zebra finch; higher vocal center; phosphorylation; transcription factor

tum (RA), and the tracheosyringeal portion of the hypoglossal nucleus (nXIIts) (Nottebohm et al., 1976, 1982). The HVC receives projections from the nucleus uvaeformis (Uva) of the thalamus directly or via the nucleus interface (NIf) (Nottebohm et al., 1982). The other is an indirect route from the HVC to the $\mathrm{RA}$, called the anterior forebrain pathway (AFP), which consists of area $\mathrm{X}$, the medial portion of the dorsolateral thalamus (DLM) and the lateral portion of the magnocellular nucleus of the anterior neostriatum (LMAN) (Okuhata and Saito, 1987; Bottjer et al., 1989). RA-projecting neurons in LMAN send axon collaterals to area X (Vates and Nottebohm, 1995). Although the role of the AFP is unclear, it is suggested that the AFP is essential for matching vocal output to the learned song template (Bottjer et al., 1984; Scharff and Nottebohm, 1991) and that some AFP nuclei are responsible for the storage of the song template (Doya and Sejnowski, 1995).

The importance of the cAMP signaling pathway for memory formation has been demonstrated in various organisms. In Drosophila, the dunce mutant, which lacks cAMP phosphodiesterase (Byers et al., 1981), and the rutabaga mutant, which has a defective calcium/calmodulin-responsive adenylate cyclase (Levin et al., 1992), have a profound learning defect. In Aplysia, injection of cAMP or inhibitors of cAMP-dependent protein kinase (PKA) block both short- and long-term facilitation (Ghirardi et al., 1992). The activation of PKA by extracellular signals results in translocation of PKA catalytic subunits (C subunit) into the nucleus and phosphorylation of a transcription factor, CREB, at $\mathrm{Ser}^{133}$ (Gonzalez and Montminy, 1989; Hagiwara et al., 1993). Phosphorylated CREB interacting with a CREB binding protein, CBP, (Chrivia et al., 1993) induces the transcription of many genes, including immediate early genes (IEGs), and promotes the de novo synthesis of proteins. Induction of a dominant negative CREB transgene blocks the long-term memory in Drosophila (Yin et al., 1994). Even in vertebrates, mice with a targeted disruption of the $\alpha$ and $\delta$ isoforms of CREB have normal short- 


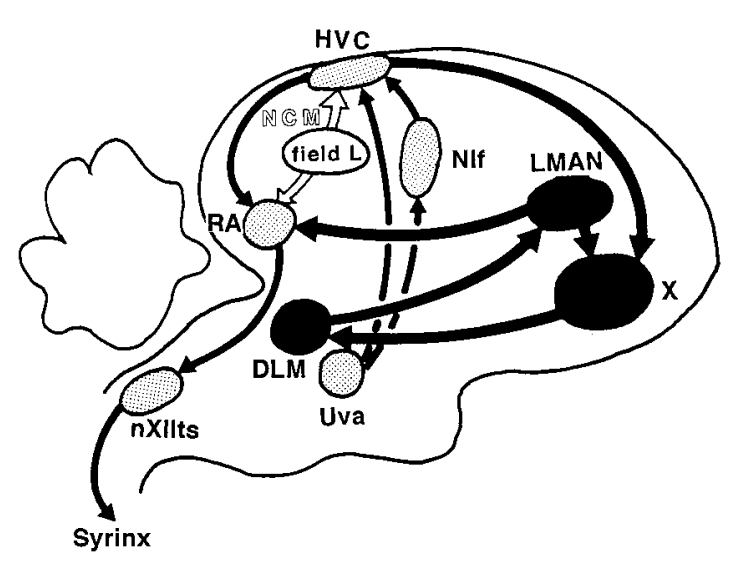

Figure 1. Schematic sagittal drawing of the avian song system. The thin lines represent the motor control pathway that is essential for the song production. The thick lines show the anterior forebrain pathway necessary for song acquisition. The white arrows show the pathway from the auditory area to the song system. Field $L$ is the primary auditory area in the bird brain. NCM, in which the immediate early gene ZENK was induced by song, is one indirect source of auditory inputs to the song system. $H V C$, Higher vocal center; $R A$, robust nucleus of the archistriatum; $n X I I t s$, tracheosyringeal part of the hypoglossal nucleus; $U v a$, nucleus uvaeformis of the thalamus; NIf, nucleus interface of the neostriatum; $X$, area $\mathrm{X}$ of the parolfactory lobe; $D L M$, medial part of the dorsolateral nucleus of the thalamus; $L M A N$, lateral magnocellular nucleus of the anterior neostriatum; NCM, caudomedial neostriatum.

term memory but are deficient in long-term memory (Bourtchuladze et al., 1994). We have found that one of the two sets of projection neurons in the HVC was immunopositive with a monoclonal antibody against human CREB-1. This prompted us to clone the CREB cDNA from the brain of the zebra finch. Consequently, we have found that the amino acid sequence of CREB is well conserved between birds and mammals, and the perfect conservation of its phosphorylation site enabled us to examine the induction of CREB in vivo in response to taperecorded conspecific songs of zebra finches with a specific antibody to the phosphorylated form of CREB.

\section{MATERIALS AND METHODS}

Animals. All birds were adult male zebra finches (Taeniopygia guttata) ( $>90 \mathrm{~d}$ old) obtained from a local breeder.

PCR cloning and sequence analysis. Total RNA was isolated from the adult zebra finch brain in ISOGEN (NIPPON GENE) according to the manufacturer's instructions. First-strand cDNA was synthesized from the $2.5 \mu \mathrm{g}$ total RNA of the zebra finch brain as the template with oligo-dT15 primer (Stratagene, Eugene, OR). N-terminal (5'-GCAGAAAGTGAAGATTCACARG-3') and C-terminal (5'-CCTTAAGTGCTTTTAGCTCYTC-3') primers were designed based on the conserved amino acid sequences of mammalian CREB isoforms. The PCR products were resolved in $1 \%$ agarose gels, and the specifically amplified band with an approximate size of $700 \mathrm{bp}$ was subcloned into pGEM-T Easy (Promega, Madison, WI). The nucleotide sequences were determined by dyeprimer cycling with ABI PRISM 377 DNA sequencing system. To extend the $5^{\prime}$ and $3^{\prime}$ ends of the cDNA fragment, the $5^{\prime}$-RACE and $3^{\prime}$-RACE System for Rapid Amplification of cDNA Ends (Life Technologies, Gaithersburg, MD) were used according to the manufacturer's instructions.

Plasmid construction and preparation of recombinant proteins. To construct pGEX-GST-zCREB, the coding region of cloned CREB cDNA from zebra finches (zCREB) was ligated into pGEX(5X-3) at the SalINotI site. pGEX-GST-zCREB was introduced into Escherichia coli (JM109), harvested for $3 \mathrm{hr}$ after introduction into the binding buffer (50 mm Tris- $\mathrm{HCl}$, pH 7.5, $1 \mathrm{~m} \mathrm{NaCl}, 5$ mм EDTA, 1 mм PMSF, 1 mм DTT, and $1 \%$ Triton $\mathrm{X}-100$ ), and bound to glutathione-Sepharose (Pharmacia, Piscataway, NJ). zCREB was eluted from the gel by digesting it with factor $\mathrm{Xa}$ (Itoham) for $2 \mathrm{hr}$ at $25^{\circ} \mathrm{C}$.
In vitro kinase reaction. pQE-PKA was incubated with bacterial CREBs or brain samples in $40 \mathrm{mM}$ HEPES, $\mathrm{pH} 7.8,10 \mathrm{mM} \mathrm{MgCl}_{2}, 2 \mathrm{~mm}$ DTT, and $1 \mu \mathrm{Ci}$ of $\left[\gamma_{-}{ }^{32} \mathrm{P}\right]$ ATP for $30 \mathrm{~min}$ at $30^{\circ} \mathrm{C}$. After incubation, samples were precipitated with trichloroacetic acid, separated with SDSpolyacrylamide gels, and exposed on x-ray film.

Immunohistochemistry. Birds were anesthetized with sodium pentobarbital and perfused through the heart with $0.1 \mathrm{~m}$ PBS, $\mathrm{pH} 7.4$, followed by $4 \%$ paraformaldehyde in $0.1 \mathrm{M} \mathrm{PBS}, \mathrm{pH}$ 7.4. The brains were post-fixed in the same solution for $8 \mathrm{hr}$ at $4^{\circ} \mathrm{C}$, and then stored overnight in a $20 \%$ phosphate-buffered sucrose solution. Sagittal sections with a thickness of $40 \mu \mathrm{m}$ were cut on a freezing microtome. Immunohistochemical staining was performed according to the avidin-biotin peroxidase complex (ABC) method. Free-floating sections were rinsed in 0.1 м PBS, pH 7.4, reacted with $0.3 \%$ hydrogen peroxide for $20 \mathrm{~min}$ at room temperature to block the activities of endogenous peroxidases before immunohistochemistry. After the sections were washed three times with $0.1 \mathrm{M}$ PBS, they were incubated for $20 \mathrm{~min}$ in $0.1 \mathrm{M}$ PBS containing $0.4 \%$ Triton $\mathrm{X}-100,4 \%$ normal goat serum (NGS), and $1 \%$ bovine serum albumin (BSA), and then incubated for $2 \mathrm{hr}$ with the primary antibody diluted in $0.1 \mathrm{M}$ PBS containing $0.4 \%$ Triton X-100, $1 \%$ NGS, and $1 \%$ BSA at $37^{\circ} \mathrm{C}$. The primary antibody was either a monoclonal antibody against human CREB-1 (1:2000 dilution; Santa Cruz Biotechnology, Santa Cruz, CA) or a polyclonal antibody against phosphorylated CREB (antiserum 5322, 1:2000 dilution) (Hagiwara et al., 1993; Yoshida et al., 1995). The sections were washed again in $0.1 \mathrm{M}$ PBS, reacted with a biotinylated goat anti-mouse or anti-rabbit IgG serum (Vectastain Elite ABC Kit, Vector Laboratories, Burlingame, CA) for $20 \mathrm{~min}$ at room temperature, washed in $0.1 \mathrm{M}$ PBS, and reacted with avidin-biotinylated horseradish peroxidase complexes (Vectastain Elite ABC Kit) for $15 \mathrm{~min}$ at room temperature. After washing, the immunoprecipitate was visualized with $0.05 \%$ 3,3'-diaminobenzidine in $0.1 \mathrm{M}$ Tris buffer, $\mathrm{pH} 7.4$, in the presence of $0.01 \%$ hydrogen peroxide for $10 \mathrm{~min}$ at room temperature. After several rinses, the sections were dehydrated and placed under coverslips. Control sections from which the primary antibody or antiserum was omitted were processed in parallel. The control sections always lacked immunoreactivity.

Double-labeling with retrograde tracer and CREB immunohistochemistry. To identify which population of HVC neurons has CREB immunoreactivity, we retrogradely labeled the area X-projecting or RA-projecting neurons with Fluoro-Red (FRe), which was kindly provided by Dr. K. Dong (Dong et al., 1996; Li and Sakaguchi, 1997). This was accomplished by stereotaxically guided pressure injections of $200-500 \mathrm{nl}$ of tracer through glass micropipettes ( $40 \mu \mathrm{m}$ in diameter) into the RA or area $\mathrm{X}$. Four birds had an injection of FRe into the RA or area $\mathrm{X}$ to reveal double-labeling with CREB immunoreactivity. Five days after injection of the tracer, sections through the HVC that contained FRe-labeled neurons were collected and processed for the immunohistochemistry of CREB as described above. The sections were photographed under a fluorescence microscope (AX 70; Olympus) using a computerized imaging system that consists of a cooled CCD camera (Photometrics) and image analysis software (IPLab Spectrum 3.0, Signal Analytics Corporation). FRe was designated as red, and CREB was designated as black. The two images were superimposed.

Auditory stimulation. Twenty-one adult zebra finches were used for the experiments. Each bird was isolated in a soundproof chamber for at least $2 \mathrm{hr}$ before the experiment, and then exposed to tape-recorded auditory stimuli, the conspecific song of a zebra finch (10 sec duration), a canary song ( $12 \mathrm{sec}$ duration), or white noise that was played through a speaker placed in the corner of the chamber and adjusted so that the average sound volume measured at the center of the cage was $\sim 75 \mathrm{~dB}$. The song stimulus was repeated at $13-15 \mathrm{sec}$ intervals for $10-60 \mathrm{~min}$. The birds were perfused immediately after the auditory stimulation.

Singing behavior. A single adult male was kept in a sound-proof chamber during the night. When the bird started singing spontaneously at dawn, the number of song bouts was scored for $30 \mathrm{~min}$ with tape- or videorecording (solo undirected singing, $n=4$ ). For the analysis of female-directed singing, a female was placed next to the male's cage to stimulate singing, and the number of song bouts was counted in the same way (female-directed singing, $n=2$ ).

Quantification of CREB-immunoreactive or phosphorylated CREBimmunoreactive cells. The density of CREB-immunoreactive (CREB-IR) or phosphorylated CREB-IR cells in the HVC and area X was determined for each bird, using a computer-assisted image analysis system. There was no difference between the medial, middle, and lateral sagittal sections. For the measurements, the two or three sagittal sections containing the middle portion of the $\mathrm{HVC}$ or area $\mathrm{X}$ from each brain were 

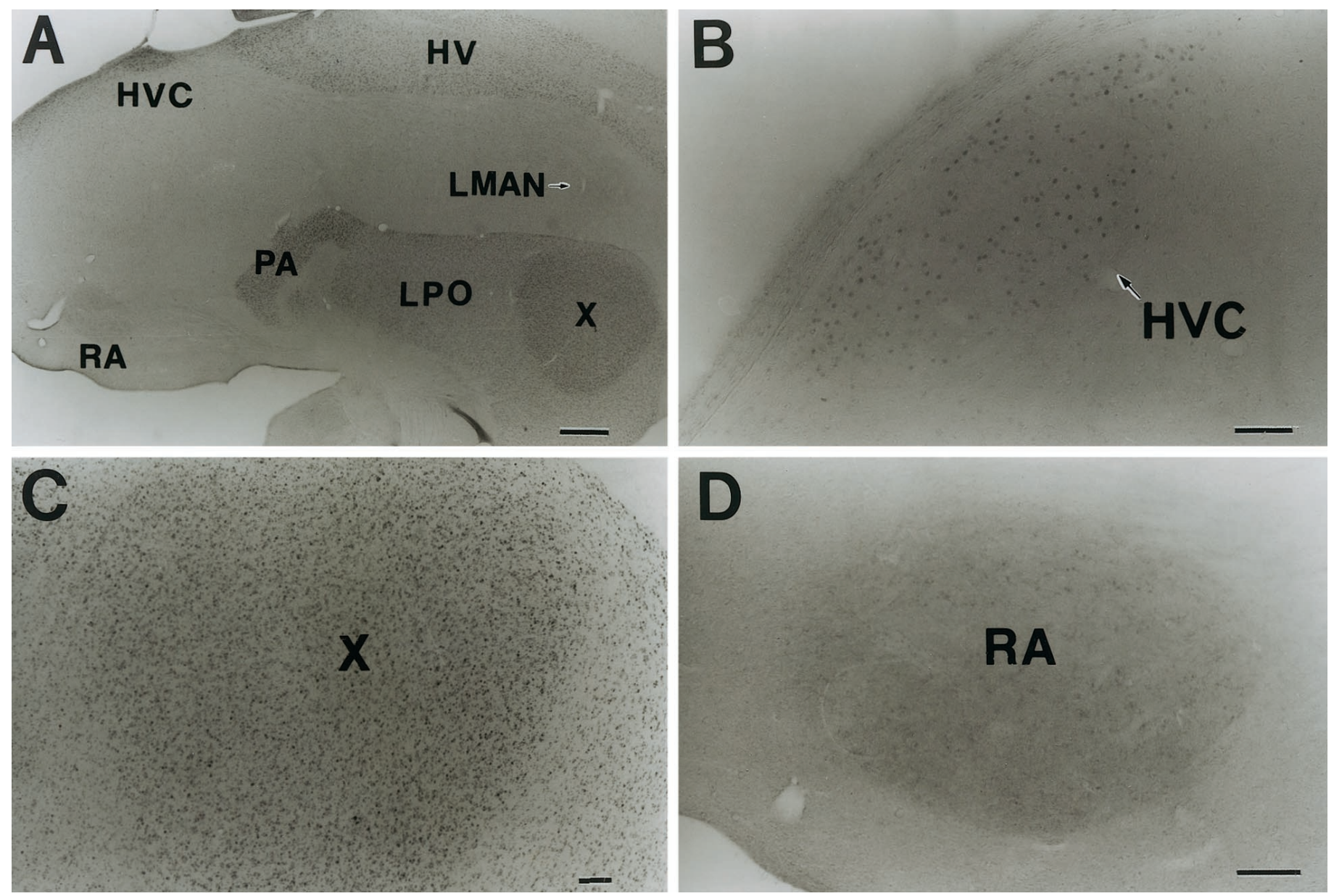

Figure 2. Immunohistochemical localization of CREB-IR structures in a sagittal section through the adult zebra finch brain. $H V$, Hyperstriatum ventrale; $P A$, paleostriatum augmentatum; $L P O$, lobus parolfactorius. $B-D$, Higher magnifications of the three main song control nuclei, $H V C(B), X(C)$, and $R A(D)$. A number of CREB-IR cell nuclei with intense staining were found in the HVC and area X $(B, C)$ but not LMAN $(A)$. In the $R A$, there were CREB-IR cell nuclei with a light staining intensity $(D)$. Dorsal is toward the top and anterior is to the right in all photos. Scale bars: $A$, $500 \mu$ m; $B-D, 100 \mu \mathrm{m}$.

examined. The images of the brain sections containing the $\mathrm{HVC}$ and area $\mathrm{X}$ were captured directly from the slides into a TIFF file at a resolution of $640 \times 400$ by a digital camera (Olympus DC10) connected to an SCSI board in a Macintosh computer. Using the MAC SCOPE software (Mitani Co.), the boundaries of the HVC or area X were drawn manually, and the area and the number of immunoreactive cells within these boundaries were measured. The cell count was taken and divided by area of HVC or area X in each section. The data presented are that of each bird's mean. The data were analyzed using a one-way ANOVA, followed by post hoc testing using Fisher's PLSD for comparing the multiple pairs of data. A level of $p<0.05$ was considered statistically significant.

\section{RESULTS}

\section{CREB immunohistochemistry}

A typical example of the distribution of CREB-IR cells can be seen in the sagittal section of the zebra finch brain (Fig. 2A). Intensely stained cells were observed throughout the hippocampus, parahippocampus, hyperstriatum ventrale (HV), paleostriatum augmentatum, and the lobus parolfactorius. In the song system and in its related regions, heavily labeled CREB-IR cells were specifically observed in the HVC (Fig. 2B), in area X (Fig. $2 C$ ), and in caudolateral $\mathrm{HV}(\mathrm{clHV})$. In the $\mathrm{HVC}$, labeled nuclei were relatively large and scattered, whereas the labeled nuclei varied in size and were densely packed in area $\mathrm{X}$ and in clHV. In LMAN, NIf, Uva, DLM, and other song-related nuclei such as the caudomedial neostriatum (NCM) and field L, only few CREB-IR cells were found (Fig. $2 A$ ). In the RA, several cells with large nuclei were faintly stained (Fig. 2D).

\section{Retrograde identification of CREB-IR cells in the HVC}

The HVC contains two types of projection neurons: RAprojecting neurons and the area X-projecting neurons. To identify the CREB-IR neurons in the HVC, four birds injected with the retrograde neurotracer FRe into the RA or area $\mathrm{X}$ were subsequently processed for CREB immunohistochemistry. Consequently, we found no CREB-like immunoreactivity in the RAprojecting neurons of the HVC (Fig. $3 A)(n=2$ birds). In contrast, many FRe-labeled area X-projecting neurons throughout HVC contained CREB-IR nuclei (Fig. $3 B)$ ( $n=2$ birds).

\section{Isolation of zebra finch CREB cDNA}

To identify the CREB-IR protein in the HVC, we tried to isolate the fragments of mammalian CREB-related cDNA from the brain of the zebra finch and designed a set of degenerate oligonucleotides as primers for the PCR based on the sequence information of the conserved amino acid sequences of human, rat, mouse, and bovine CREBs. RT-PCR was performed as described in Materials and Methods. Amplified PCR products with an approximate 

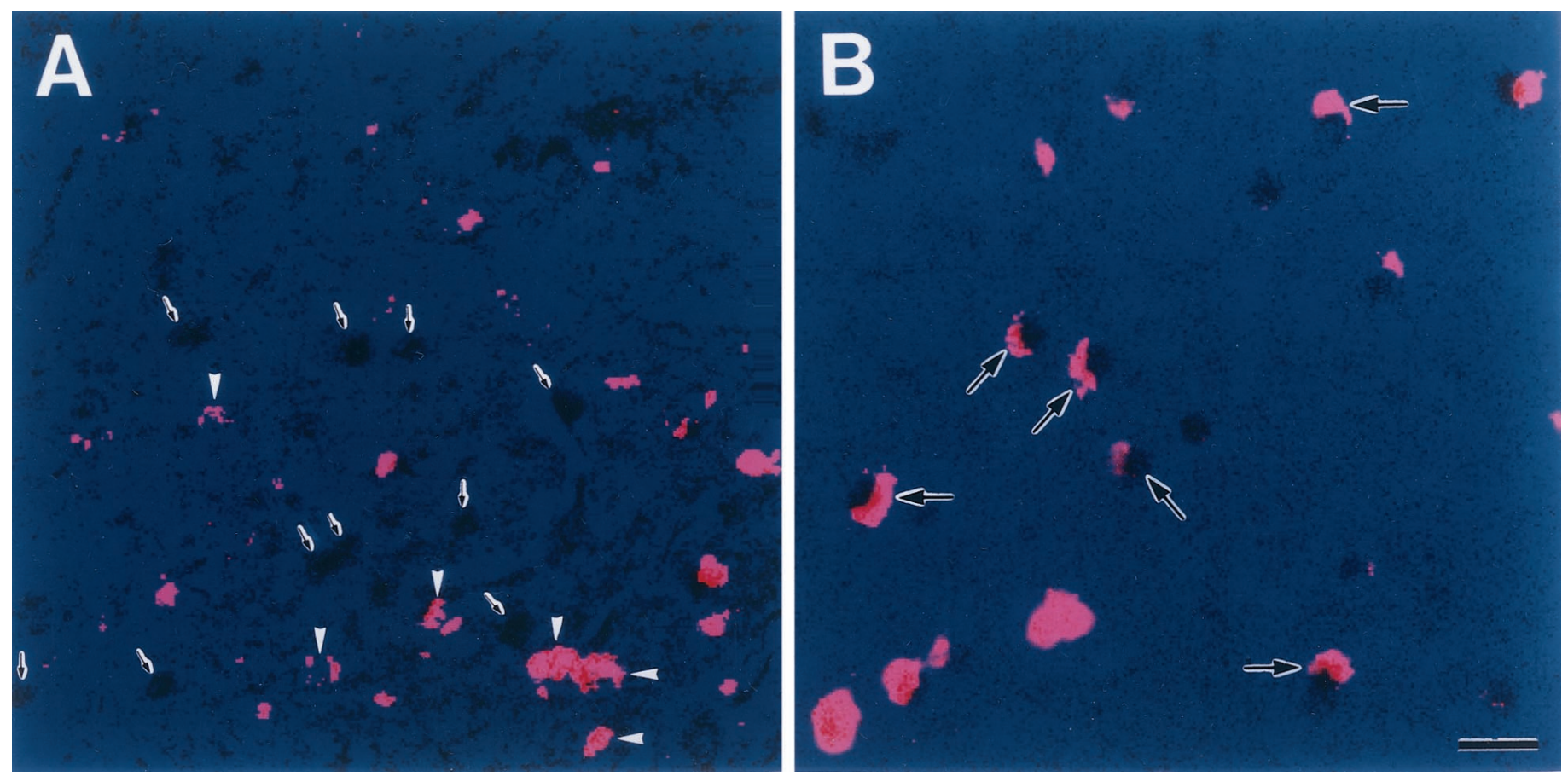

Figure 3. Combined neuron labeling in the HVC with a retrograde tracer, FRe. $A$, Ipsilateral RA, injected with FRe. Retrogradely labeled RA-projecting neurons within HVC (pink label; white arrowheads point to tracer-labeled neurons) do not overlap with CREB-IR cell nuclei (black label; arrows point to CREB-IR nuclei without cytoplasmic retrograde tracer). $B$, Double-labeled HVC neurons were projected in area $\mathrm{X}$ and were visible when FRe was injected into area X (arrows point to typical neurons). Scale bar, $20 \mu \mathrm{m}$.

size of 700 bp were subcloned into the plasmid vector and sequenced. The full-length cDNA clone (984 bp) obtained by $5^{\prime}-$ and $3^{\prime}$-RACE shows an $84 \%$ identity to rat $\delta$ CREB at the nucleic acid sequence and encodes an open reading frame of 327 amino acids. The deduced amino acid sequence shows a strikingly high conservation between mammals and birds. zCREB cloned from the brain is highly homologous to mammalian $\delta$ CREB $(95,97,98$, and $97 \%$ identity to human, rat, mouse, and bovine $\delta$ CREB, respectively) (Fig. 4A). Between zebra finches and rats, the Q1 and Q2 (glutamine-rich regions) and the DBD/LZ (DNA binding/leucine zipper) domain have 95, 97, and 98\% identity, respectively. The kinase-inducible domain (KID) showed the highest conservation at $98 \%$. The putative phosphoacceptor site by PKA in $\mathrm{KID}$ is enclosed by a rectangle in Figure $4 \mathrm{~B}$. Bacterially expressed zCREB was recognized by the anti-CREB-1 monoclonal antibody, which was used for the immunohistochemical analysis in Figures 2 and 3 (Fig. 5A, lane 4 ). The antibody gave a single band of $\sim 45 \mathrm{kDa}$ with homogenized samples from the whole brain or the HVC region of zebra finches (Fig. 5A, lanes 1, 2).

\section{Recognition of phosphorylated zCREB by antiserum 5322}

We have developed a polyclonal antiserum that recognizes mammalian CREB only after it has been phosphorylated by PKA. This antiserum (5322) can readily discriminate between the phosphorylated and dephosphorylated forms, thereby enabling us to detect the activation of CREB in response to extracellular signals in vivo. As mentioned above, zCREB has a putative PKA phosphoacceptor site at $\operatorname{Ser}^{119}$ (equivalent site to $\operatorname{Ser}^{133}$ of $\alpha$ CREB) and was readily phosphorylated by PKA in vitro (Fig. $5 B$ ). Because the epitope for the antibody is perfectly conserved between mammals and birds as shown in the inset of Figure $4 B$, we have examined the cross-reactivity of antiserum 5322 against phos- phorylated zCREB on Western blots. The antiserum 5322 could recognize the recombinant $z C R E B$ protein in a phosphorylationdependent manner (Fig. 5C, lane 4). A $45 \mathrm{kDa}$ CREB band from crude homogenates of the zebra finch brain was detected only after incubating with PKA and ATP (Fig. 5C, lane 8).

\section{Phosphorylation of zebra finch CREB by song presentation}

To determine whether the $\mathrm{zCREB}$ was phosphorylated in area $\mathrm{X}$ and $\mathrm{HVC}$ in response to a tape-recorded conspecific song of zebra finches, we used the antiserum 5322 for immunohistochemistry. Phosphorylated CREB-IR (PCREB-IR) was detectable only in the nuclei of HVC cells of the birds hearing the conspecific song (Fig. 6D,F), whereas CREB-IR in HVC was not affected by the sound condition (Fig. 6A,B). The number of PCREB-IR neurons in the HVC increased gradually with a peak of $\sim 3$.4-fold of the control level within $30 \mathrm{~min}$ (Fig. 7). At the time of greatest labeling, $83 \%$ of CREB-IR cells were phosphorylated. Thereafter, phosphorylation decreased steadily, falling to $71 \%$ of the peak level by $60 \mathrm{~min}$, suggesting that CREB was gradually dephosphorylated, although the sample number is not adequate at several time points. The time dependency of CREB phosphorylation is in good accord with our previous analysis in the cultured PC12 cells (Hagiwara et al., 1992). In contrast to the HVC, no significant change was seen in the number of either CREB-IR cells $(n=4)$ or PCREB-IR cells $(n=4)$ as compared with the control value $(n=3)$ in area $\mathrm{X}$, even after the conspecific song was heard for $30 \mathrm{~min}$ (Fig. 8). To examine whether induced CREB phosphorylation is specific for the conspecific song of zebra finches, three kinds of tape-recorded auditory stimuli were tested: white noise, canary song, and a conspecific song of the zebra finch. As summarized in Figure 9, quantitative analysis indicated that the number of CREB-IR cells was not significantly 


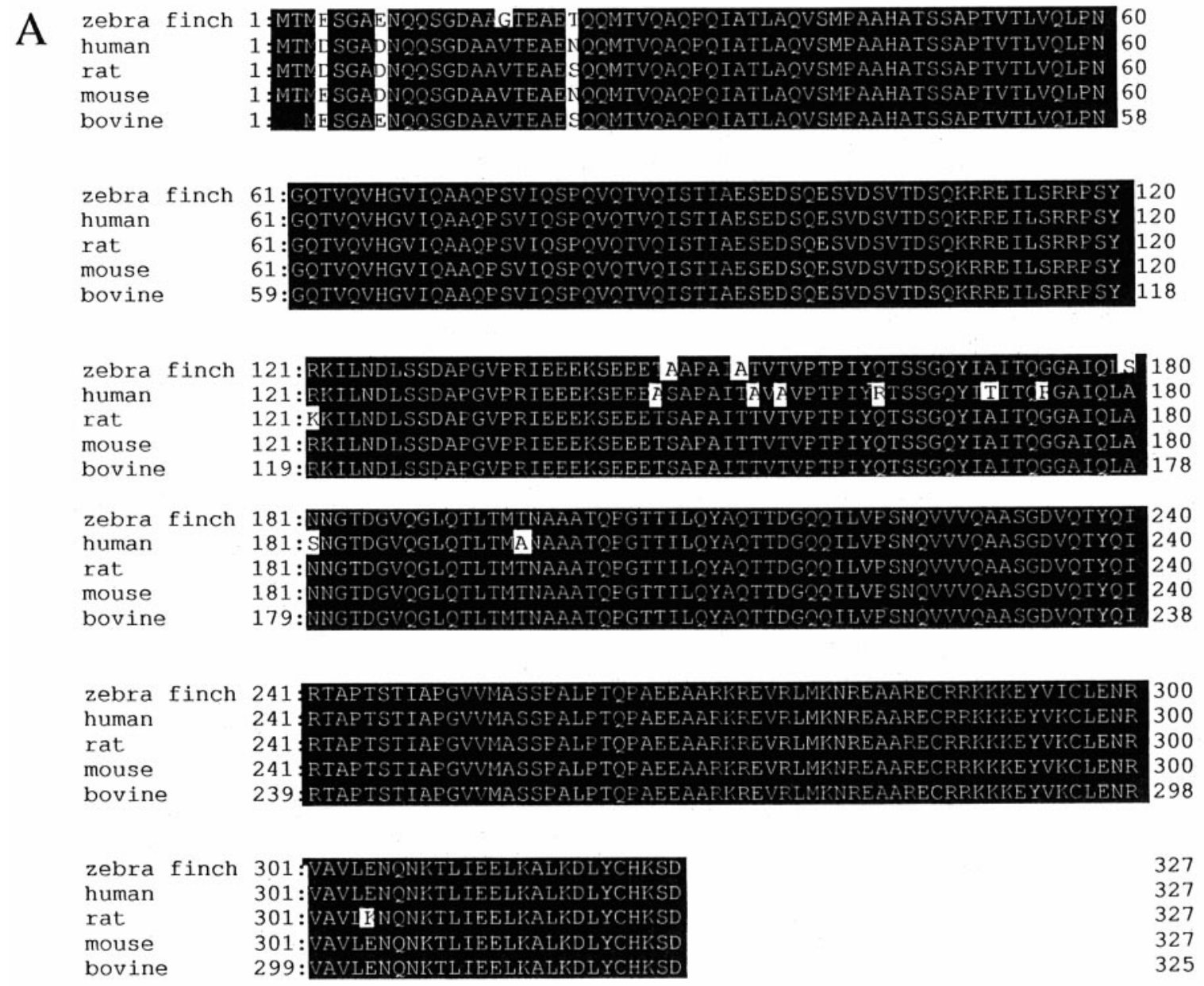

B

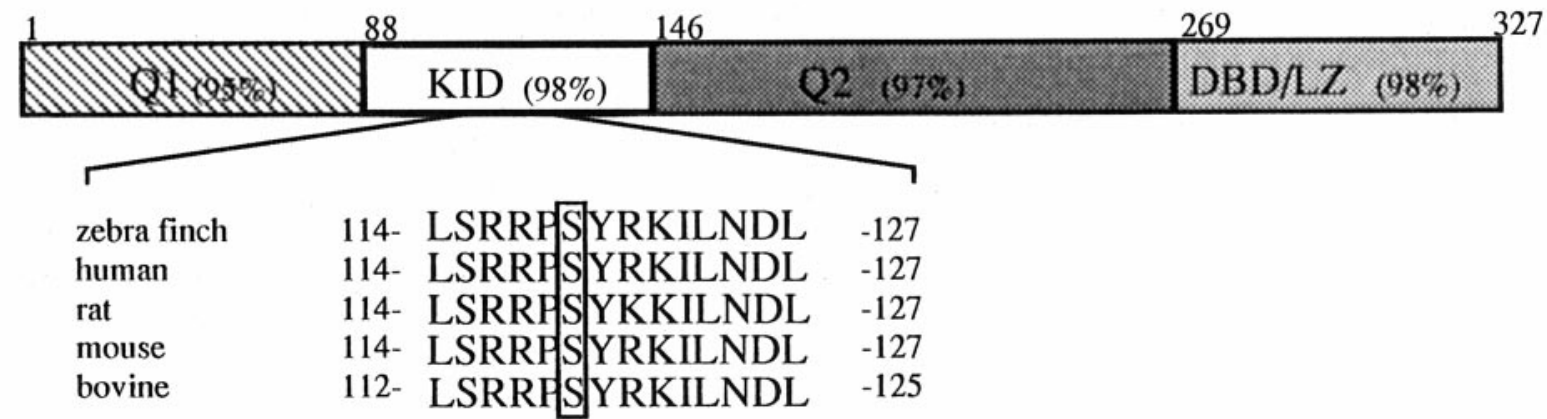

Figure 4. Primary structure of zebra finch CREB. $A$, The zebra finch CREB sequence was aligned with mammalian CREB proteins (human, rat, mouse, and bovine $\delta$ CREB). Amino acids that are identical in all five sequences are displayed with the figure and ground reversed. The GenBank accession numbers for the human, rat, mouse, and bovine sequences are X60003, X60002, s20955, and AF006042, respectively. B, The domains of CREB are schematically represented. The small numbers refer to amino acid residues at the boundaries of each domain. Q1, Q2, Glutamine-rich regions; KID, kinase-inducible domain; $D B D / L Z$, DNA-binding/leucine zipper domain. The percentages in each domain represent the percentage identity of CREB amino acid sequences between zebra finch and rat. The epitope for antiserum 5322 is shown below, and the putative protein kinase A (PKA) phosphoacceptor site is enclosed by a rectangle. 

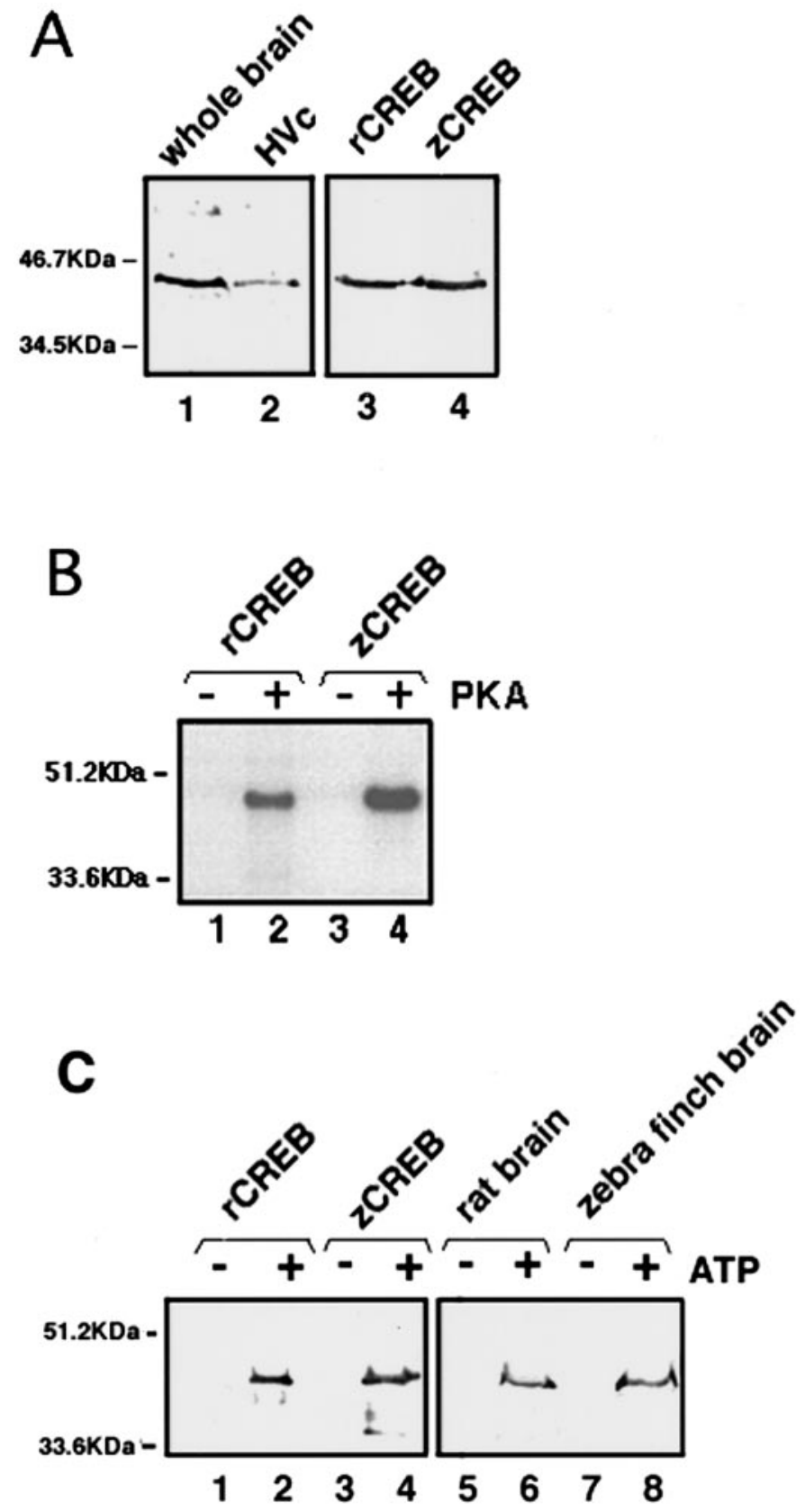

Figure 5. Immunoblots of zebra finch CREB. $A$, Immunoblots of zebra finch homogenates (whole brain, lane 1; HVc region, lane 2) and recombinant CREB proteins (rat, lane 3; zebra finch, lane 4) detected with the CREB-1 monoclonal antibody. This antibody does not discriminate between phosphorylated and unphosphorylated CREB. B, In vitro phosphorylation of recombinant zebra finch CREB with the catalytic subunit of protein kinase A $(P K A)$. Zebra finch recombinant CREB $(z C R E B)$ protein was incubated with $(+)$ or without $(-)$ the catalytic subunit of PKA in the reaction mixtures containing $\left[\gamma^{-}{ }^{32} \mathrm{P}\right] \mathrm{ATP}$ and resolved by SDSPAGE. Phosphorylation of recombinant rat CREB $(r C R E B)$ is shown as a positive control. $C$, Immunoblots of unphosphorylated (ATP-) or phosphorylated $(\mathrm{ATP}+)$ CREB. Recombinant CREB proteins (lanes 1-4) and crude homogenates of brain tissues (lanes 5-8) were incubated with or without ATP in the presence of PKA. Only the phosphorylated form of zCREB in the brain tissue (lane 8) and recombinant zCREB (lane 4 ) were recognized with antibody 5322. A crude rat homogenate (lane 6) and recombinant CREB (lane 2) are shown as positive controls. The positions (in kilodaltons) of the molecular size markers are shown to the left of the gels. different between control $(n=5)$ and song presentation $(n=5)$ and that the number of PCREB-IR cells induced by the conspecific song $(n=5)$ was dramatically increased after the conspecific song was heard for $30 \mathrm{~min}$. However, the presentation of either the white noise $(n=5)$ or the canary song $(n=3)$ for $30 \mathrm{~min}$ caused no induction of the CREB phosphorylation in the HVC.

\section{No induction of CREB phosphorylation in HVC by singing}

In the song control nuclei, according to Jin and Clayton (1997), an immediate early gene $\mathrm{ZENK}$ is induced in the RA, HVC, LMAN, and area $\mathrm{X}$ by the motor act of singing. To determine whether the CREB phosphorylation in the HVC is specific to auditory stimulation or induced by the motor activity associated with song production, we examined the PCREB-IR of solosinging or female-induced singing birds. Figure 10 shows the relationship between amount of singing and PCREB-IR cells in the HVC. The numbers of PCREB-IR cells were not significantly different between control $(n=4)$ and the undirected singing birds who sang 30 or more song bouts for $30 \mathrm{~min}(n=3$; from data in Fig. 10). Accordingly, CREB phosphorylation was not induced by undirected singing. Moreover, no induction of PCREB-IR was observed in the HVC of female-directed singing birds (Fig. $10, \mathbf{0})$.

\section{DISCUSSION}

CREB is the key molecule for the formation of long-term memory. We have now focused on the functional characterization of zCREB in the song system of the zebra finch brain. Immunohistochemical analysis revealed that CREB-IR neurons were found in two nuclei of the song system: the HVC and area X. By combining retrograde tracers with the immunohistochemistry, we have determined that the CREB-IR protein is expressed only in the $\mathrm{HVC}$ neurons that project their dendrites into area $\mathrm{X}$. Thereafter, we cloned CREB cDNA from the zebra finch brain. CREB isoforms are generated from a gene by alternative splicing, and the zCREB was highly homologous to that of mammalian $\delta$ CREB. Because the phosphorylation site was well conserved between the avian and the mammalian CREB, we used an antibody that is specific for phosphorylated CREB for immunostaining and found that zCREB in area X-projecting HVC neurons is phosphorylated by exposing it to the conspecific songs of zebra finches. These results strongly suggest that zCREB is an essential molecule for the transduction of auditory information into longlasting traces in the song system.

The HVC of the neostriatum is the center of the forebrain, which is critical in song production (Nottebohm et al., 1976; Vu et al., 1994; Yu and Margoliash, 1996), perception (Brenowitz, 1991), and learning. It receives auditory inputs from the field L complex, the primary forebrain auditory nucleus, and other forebrain auditory regions connected with the field L complex (Vates et al., 1996) and responds to the complex auditory stimuli (Katz and Gurney, 1981; Margoliash, 1983; Margoliash and Fortune, 1992; Lewicki, 1996). Interestingly, HVC neurons that are highly selective for the bird's own song respond rather weakly to the conspecific song. They respond to the auditory stimuli under anesthesia but do not respond to the stimuli under the awake stage (Schmidt and Konishi, 1998). These facts suggest that the HVC acts as a gateway for auditory information of the song system. There are two major classes of projection neurons in the HVC: those projecting to the RA in the descending motor 

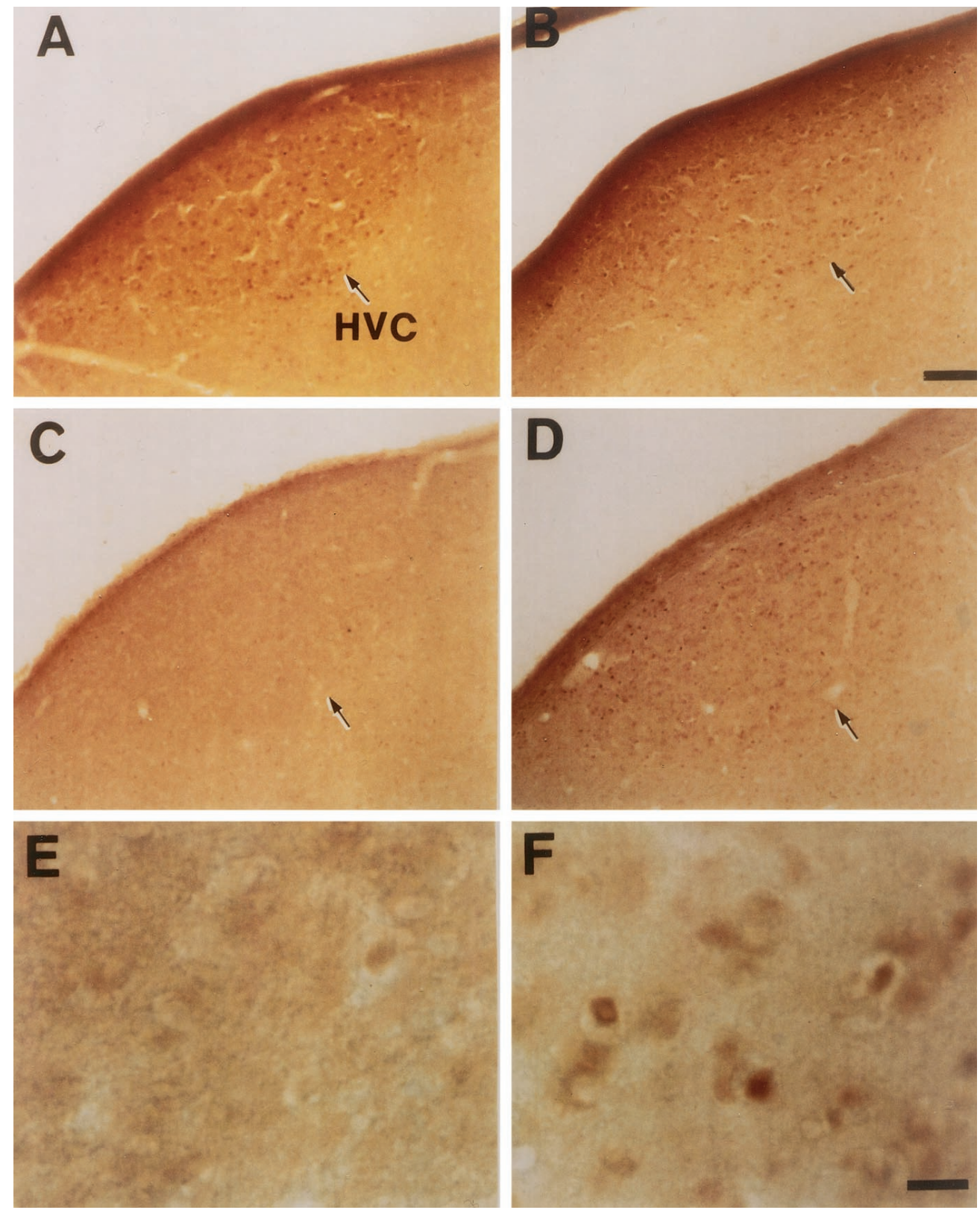

Figure 6. Song-induced CREB phosphorylation in the HVC. Shown are CREB-IR $(A, B)$ and PCREB-IR $(C-F)$ cell nuclei in the HVC after hearing white noise $(A, C, E)$ or a zebra finch conspecific song $(B, D, F)$ for $30 \mathrm{~min}$. The song induced phosphorylation of CREB in the HVC, whereas white noise did not. CREB immunoreactivity was not affected after either stimuli. $E$ and $F$ are higher magnifications of the HVCs shown in $C$ and $D$, respectively. The sections were cut in the sagittal plane. Dorsal is toward the top and anterior is to the right in all photos. Scale bars: $B$, $100 \mu \mathrm{m} ; F, 20 \mu \mathrm{m}$. pathway and those projecting to area $\mathrm{X}$ in the AFP. Kimpo and Doupe (1997) provided the first direct evidence that the two kinds of HVC projection neurons are functionally distinct, demonstrating that singing induced c-fos only in the RA-projecting neurons in the HVC.

In the present study, we found that only neurons projecting to the area $\mathrm{X}$ in the $\mathrm{HVC}$ intensely express $\mathrm{zCREB}$, which is phosphorylated only when the zebra finch hears a conspecific song, but not to that of the heterospecific song. Although the observed CREB phosphorylation in HVC seems to be a specific response to auditory stimulation, this might be motor-driven as is the case of immediate early genes expression (Kimpo and Doupe, 1997; Javis et al., 1998). Our last experiments showed that the CREB phosphorylation was not induced by female-directed or undirected singing, denying the latter possibility (Fig. 10). CREB phosphorylation in HVC may have some relevance to the perception and discrimination of conspecific song reported by Brenowitz (1991).
Area X, which receives a projection from the HVC, is the largest nucleus in the AFP. However, both the local neuronal circuits within area $\mathrm{X}$ and its physiological function remain unknown. Lesions of area $\mathrm{X}$ in juveniles resulted in songs that remain variable (Scharff and Nottebohm, 1991). Area X receives dopaminergic inputs from a midbrain nucleus, which are used for reinforcement or attention signals (Lewis et al., 1981; Bottjer, 1993; Soha et al., 1996). From these observations, Doya and Sejnowski (1995) proposed a reinforcement model of song learning. They hypothesized that both the storage of the song template and a template matching mechanism exist in area $X$. In the present study, we found a large number of CREB-IR neurons throughout area X. However, we did not observe song-induced phosphorylation of CREB in area $\mathrm{X}$ of adult zebra finches. Because song acquisition is limited to the sensitive period, examination of song-induced CREB phosphorylation during the sensitive period may provide a new insight into the function of area $\mathrm{X}$. 


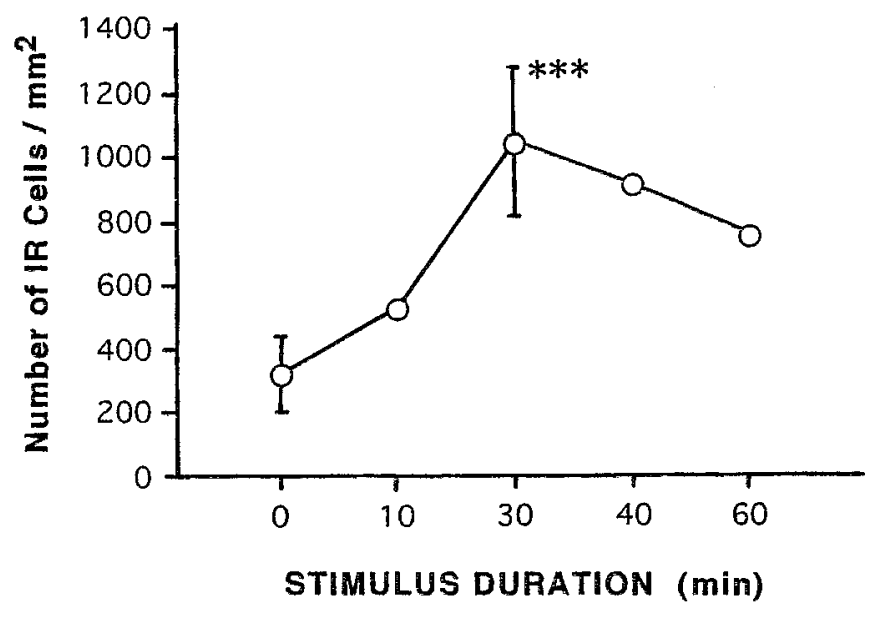

Figure 7. Time-dependency of song-induced phosphorylation of CREB in the HVC. Values represent the number of phosphorylated CREB-IR cells $/ \mathrm{mm}^{2}$ in HVC: $n=4$ for $0 \mathrm{~min}, n=5$ for $30 \mathrm{~min}$, and $n=1$ for the others. Values for 0 and $30 \mathrm{~min}$ are the mean $\pm \mathrm{SD}$. The difference between 0 and $30 \mathrm{~min}$ is statistically significant $(p<0.001)$.

Little is known about the cellular process by which song templates are consolidated into stable and long-lasting song memories. Chew et al. (1995) reported that the injection of protein or RNA synthesis inhibitors blocked the long-lasting memory formation of a repeated conspecific song. Recent studies about song-induced changes in gene expression have offered a new perspective on song learning. Mello et al. (1992) showed that the playback of a song induced an IEG called ZENK in the auditory area, the NCM of adult canaries, and zebra finches that receives projections from field L and projects toward the HVC (Vates et al., 1996). In the song control nuclei, according to Jin and Clayton (1997), ZENK is induced in the RA, HVC, LMAN, and area X by the motor act of singing. Furthermore, Kimpo and Doupe (1997) reported that singing induced a different IEG, c-fos, in the HVC and RA. Zif-268, the mammalian counterpart of ZENK, and c-fos have a CRE in their promoter regions (Montminy et al., 1986), and both genes are induced by CREB in mammalian cells. The results presented here indicated that the phosphorylation of CREB in area X-projecting neurons in the HVC of adult zebra finches was induced by listening to a conspecific song. Analysis of

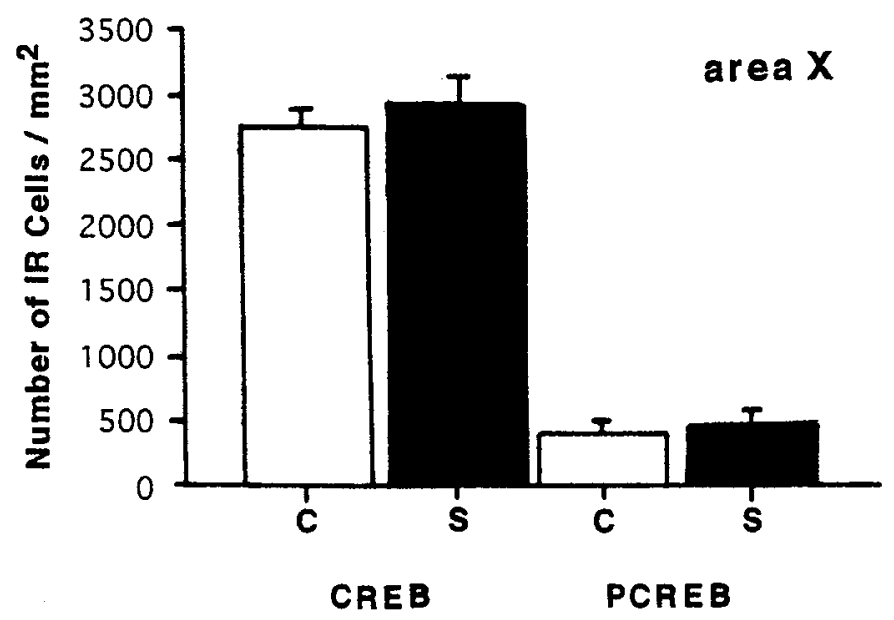

Figure 8. Quantitative analysis of CREB-IR and PCREB-IR nuclei induced in area $\mathrm{X}$ by hearing a song. $C$, Control; $S$, zebra finch conspecific song for $30 \mathrm{~min}$. Values are the mean $\pm \mathrm{SD}$.

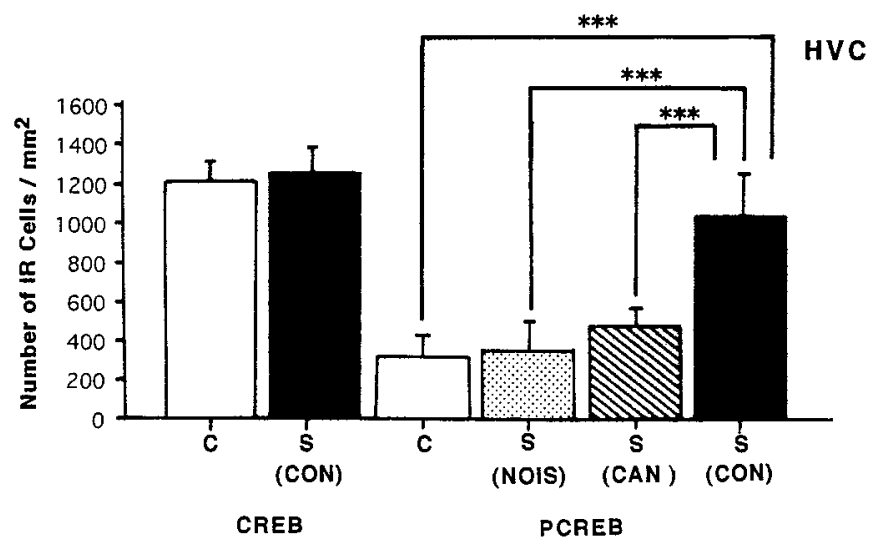

Figure 9. Comparative analysis of CREB-IR and PCREB-IR nuclei induced by hearing three auditory stimuli: white noise (NOIS), a canary song $(C A N)$, and a zebra finch conspecific song $(C O N)$. Values are the mean $\pm \mathrm{SD}$. The differences between the conspecific song group and the other groups are statistically significant $(* * * p<0.001)$.

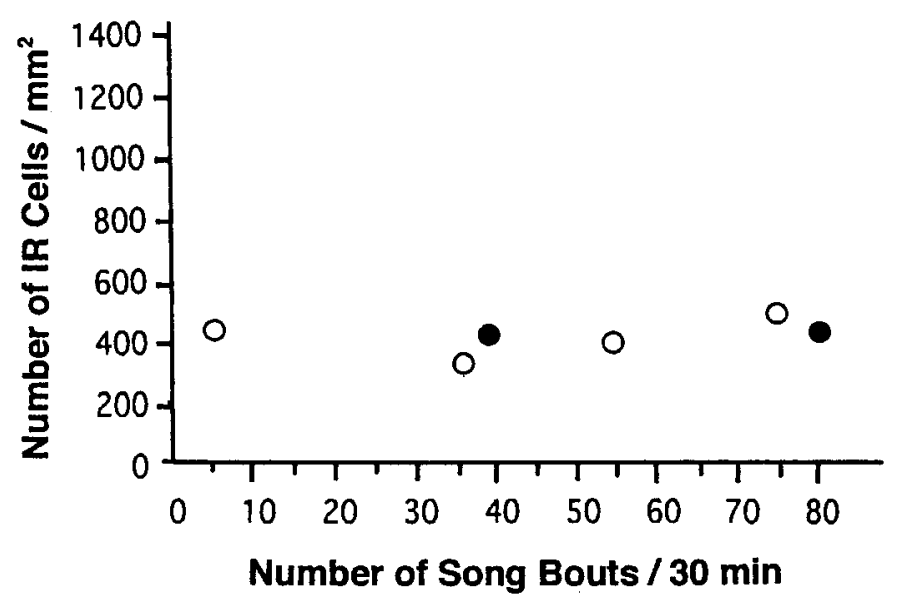

Figure 10. No induction of CREB phosphorylation in HVC by undirected or directed singing. The number of PCREB-IR cells $/ \mathrm{mm}^{2}$ in the HVC was plotted as a scatter diagram against the number of song bouts during 30 min. $\bigcirc$, Undirected singing (solo); $\bullet$, directed singing.

Fos-lacZ expression in the CNS and in cultured cells, however, demonstrated that regulation of c-fos expression requires multiple transcriptional control elements of the promoter (Robertson et al., 1995). Phosphorylated CREB should regulate the transcription of many genes including IEGs, but the involvement of CREB activation in transcriptional regulation of ZENK and c-fos in the NCM should be examined carefully. The phosphorylation of CREB in the HVC neurons is the first clue to song-induced changes of gene expression in the song control nuclei. The picture obtained from other experimental systems indicated that CREmediated gene expression via CREB activation leads to long-term neural circuit alterations during the consolidation of long-term memory. The identification of the CREB-activated genes in the song control nuclei during the learning period will be required.

\section{REFERENCES}

Bottjer S (1993) The distribution of tyrosine hydroxylase immunoreactivity in the brains of male and female zebra finches. J Neurobiol 24:51-69.

Bottjer S, Miesner E, Arnold A (1984) Forebrain lesions disrupt development but not maintenance of song in passerine birds. Science 224:901-903. 
Bottjer S, Halsema K, Brown S, Miesner E (1989) Axonal connections of a forebrain nucleus involved with vocal learning in zebra finches. J Comp Neurol 279:312-316.

Bourtchuladze R, Frenguelli B, Blendy J, Cioffi D, Schutz G, Silva AJ (1994) Deficient long-term memory in mice with a targeted mutation of the cAMP-responsive element-binding protein. Cell 79:59-68.

Brenowitz EA (1991) Altered perception of species-specific song by female birds after lesions of a forebrain nucleus. Science 251:303-305.

Byers D, Davis RL, Kiger JAJ (1981) Defect in cyclic AMP phosphodiesterase due to the dunce mutation of learning in Drosophila melanogaster. Nature 289:79-81.

Chew S, Mello C, Nottebohm F, Jarvis E, Vicario D (1995) Decrements in auditory responses to a repeated conspecific song are long-lasting and require two periods of protein synthesis in the songbird forebrain. Proc Natl Acad Sci USA 92:3406-3410.

Chrivia JC, Kwok RP, Lamb N, Hagiwara M, Montminy MR, Goodman RH (1993) Phosphorylated CREB binds specifically to the nuclear protein CBP. Nature 365:855-859.

Dong K, Qu T, Ahmed FAKM, Zhang L, Yamada K, Guison GN, Miller M, Yamadori T (1996) Fluoro-Green and Fluoro-Red: two new fluorescent retrograde tracers with a number of unique properties. Brain Res 736:61-67.

Doya K, Sejnowski T (1995) A novel reinforcement model of birdsong vocalization learning. Adv Neural Inf Process Syst 7:101-108.

Ghirardi M, Braha O, Hochner B, Montarolo PG, Kandel ER, Dale N (1992) Roles of PKA and PKC in facilitation of evoked and spontaneous transmitter release at depressed and nondepressed synapses in Aplysia sensory neurons. Neuron 9:479-489.

Gonzalez GA, Montminy MR (1989) Cyclic AMP stimulates somatostatin gene transcription by phosphorylation of CREB at serine 133. Cell 59:675-680.

Hagiwara M, Alberts A, Brindle P, Meinkoth J, Feramisco J, Deng T, Karin M, Shenolikar S, Montminy M (1992) Transcriptional attenuation following cAMP induction requires PP-1-mediated dephosphorylation of CREB. Cell 70:105-113.

Hagiwara M, Brindle P, Harootunian A, Armstrong R, Rivier J, Vale W, Tsien R, Montminy MR (1993) Coupling of hormonal stimulation and transcription via the cyclic AMP-responsive factor CREB is rate limited by nuclear entry of protein kinase A. Mol Cell Biol 13:4852-4859.

Immelmann K (1969) Song development in the zebra finch and other estrildid finches. In: Bird vocalization (Hinde RA, ed) pp 61-74. New York: Cambridge UP.

Javis ED, Scharaff C, Grossman MR, Ramos JA, Nottebohm F (1998) For whom the bird sings: context-dependent gene expression. Neuron 21:775-788.

Jin H, Clayton D (1997) Localized changes in immediate-early gene regulation during sensory and motor learning in zebra finches. Neuron 19:1049-1059.

Kaang B-K, Kandel ER, Grant SGN (1993) Activation of cAMPresponsive genes by stimuli that produce long-term facilitation in Aplysia sensory neurons. Neuron 10:427-435.

Katz L, Gurney M (1981) Auditory responses in the zebra finch's motor system for song. Brain Res 211:192-197.

Kimpo R, Doupe A (1997) FOS is induced by singing in distinct neuronal populations in a motor network. Neuron 18:315-325.

Konishi M (1965) The role of auditory feedback in the control of vocalization in the white-crowned sparrow. Z Tierpsychol 22:584-599.

Levin LR, Han PL, Hwang PM, Feinstein PG, Davis PG, Reed RR
(1992) The Drosophila learning and memory gene rutabaga encodes a $\mathrm{Ca}^{2+} /$ calmodulin-responsive adenylate cyclase. Cell 68:479-489.

Lewicki M (1996) Intracellular characterization of song-specific neurons in the zebra finch auditory forebrain. J Neurosci 16:5855-5863.

Lewis J, Ryan S, Arnold A, Butcher L (1981) Evidence for a catecholaminergic projection to area $\mathrm{X}$ in the zebra finch. J Comp Neurol 196:347-354.

Li R, Sakaguchi H (1997) Cholinergic innervation of the song control nuclei by the ventral paleostriatum in the zebra finch: a double-labeling study with retrograde fluorescent tracers and choline acetyltransferase immunohistochemistry. Brain Res 763:239-246.

Margoliash D (1983) Acoustic parameters underlying the responses of song-specific neurons in the white-crowned sparrow. J Neurosci 3:1039-1057.

Margoliash D, Fortune E (1992) Temporal and harmonic combination-sensitive neurons in the zebra finch's HVc. J Neurosci 12: $4309-4326$.

Mello C, Vicario D, Clayton D (1992) Song presentation induces gene expression in the songbird forebrain. Proc Natl Acad Sci USA 89:6818-6822.

Montminy MR, Sevarino KA, Wagner JA, Mandel G, Goodman RH (1986) Identification of cyclic-AMP-responsive element within the rat somatostatin. Proc Natl Acad Sci USA 83:6682-6686.

Nottebohm F, Stokes T, Leonard C (1976) Central control of song in the canary, Serius canaria. J Comp Neurol 165:457-486.

Nottebohm F, Kelley D, Paton J (1982) Connections of vocal control nuclei in the canary telencephalon. J Comp Neurol 207:344-357.

Okuhata S, Saito N (1987) Synaptic connections of thalamo-cerebral vocal nuclei of the canary. Brain Res Bull 18:35-44.

Robertson LM, Kerppola TK, Vendrell M, Luk D, Smeyne RJ, Bocchiaro C, Morgan JI, Curran T (1995) Regulation of c-fos expression in transgenic mice requires multiple interdependent transcription control elements. Neuron 14:241-252.

Scharff C, Nottebohm F (1991) A comparative study of the behavioral deficits following lesions of various parts of the zebra finch song system: implications for vocal learning. J Neurosci 11:2896-2913.

Schmidt MF, Konishi M (1998) Gating of auditory responses in the vocal control system of awake songbirds. Nature Neurosci 1:513-518.

Soha J, Shimizu T, Doupe A (1996) Development of the catecholaminergic innervation of the song system of male zebra finch. J Neurobiol 29:473-489.

Vates G, Nottebohm F (1995) Feedback circuitry within a song learning pathway. Proc Natl Acad Sci USA 92:5139-5143.

Vates G, Broome B, Mello C, Nottebohm F (1996) Auditory pathways of caudal telencephalon and their relation to the song system of adult male zebra finches (Taenopygia guttata). J Comp Neurol 366:613-642.

Vu ET, Mazurek ME, Kuo Y-C (1994) Identification of a forebrain motor programming network for the learned song of zebra finches. J Neurosci 14:6924-6934.

Yin JPC, Wallach JS, Del Vecchio M, Wilder EL, Zhou H, Quinn WG, Tully $\mathrm{T}$ (1994) Induction of a dominant negative CREB transgene specifically blocks long-term memory in Drosophila. Cell 79:49-58.

Yoshida K, Imaki J, Matsuda H, Hagiwara M (1995) Light-induced CREB phosphorylation and gene expression in rat retinal cells. J Neurochem 65:1499-1504.

Yu AC, Margoliash D (1996) Temporal hierarchical control of singing in birds. Science 251:303-305. 